\title{
Working in Twilight Zones: Some Reflections on the Conceptual and Methodological Issues of Inter-Disciplinary Approach in Public Health
}

\author{
Kesavan Rajasekharan $\mathrm{N}^{1}$, Seval A2*, Lekha D Bhat ${ }^{3}$, Lucy G ${ }^{4}$ and Anant \\ $\mathbf{K}^{5}$ \\ ${ }^{1}$ Global Institute of Public Health and Santhigiri Research Foundation, \\ Thiruvananthapuram, Kerala, India \\ ${ }^{2}$ Baskent University, School of Medicine, Department of Public Health, Turkey \\ ${ }^{3}$ Department of Epidemiology and Public Health, India \\ ${ }^{4}$ Department of Bio-Sciences, Mar Athanasius College for Advanced Studies, India \\ ${ }^{5}$ Xavier Institute of Social Services, India
}

*Corresponding author: Seval Akgun, Professor, Department of Public Health, Baskent University, Turkey, Email: sevalak2007@gmail.com

\section{Abstract}

In recent years, there is a proliferation of studies on public health with an interdisciplinary orientation and in many cases the current public health professionals need to transcend the disciplines or areas they are equipped to handle. We feel that this is indeed a paradigmatic predicament for people who belong to some specific disciplines. This paper is a review work which uses the iterative approach to reformulate, revise and report conceptual and methodological levels involved while working in an inter-disciplinary platform and in an academic domain. It is now well-accepted that given the biological, medical, behavioural, cultural, institutional, sociological, economic, historical and political facets of health, an inter-disciplinary framework is desirable in public health in order to make meaningful contributions. We need to address three levels in this process. The first level is to consider health (ill-health to be specific) as a problem which has to be resolved. The second level is to consider health as a need to alleviate the suffering due to health problems. At the third level is the international domain where the focus has to be on the imbalances in the world system which sustains poverty and inequality in individual countries. With respect to specific phenomenon in health, there are a number of factors which are related to conceptual, operational, technical-methodological and institutional domains. This complexity is discussed in this paper by taking the case of decentralization in health care. It is concluded that public health needs this tradition in order to strengthen its application and utility to make health services more meaningful to the people.

Keywords: Paradigmatic Predicament; Public Health; Twilight Zones 


\section{Introduction}

The conceptual and methodological problems plaguing the mainstream disciplines in India have been wellarticulated earlier on a number of platforms. However, there is a need to address the paradigmatic predicament of those working in twilight areas, often called as interdisciplinary disciplines such as public health.

In recent years there is a proliferation of studies on socially oriented public health-related themes largely as a result of renewed interest in the area and change in the funding strategies of mainly international agencies. Several universities and research institutes have initiated study programs and research in this field and substantial contributions have been made in a number of disciplines. The consequence is that the problem of public health which requires a multidimensional analysis is approached more or less similar to the six blind men examining an elephant! [1]. An entirely different trajectory is the one adopted by what can be called as the fact-finding approach which is largely outside the academic system especially by non-governmental agencies undertaking research. These are largely investigations carried out to facilitate the projects which are externally funded. A large number of such studies are in the area of HIV/AIDS. Thus, there are two broad categories of public health, one which is still predominantly academic in orientation with its syncretic characteristics and the other which is practiced outside the academic institutions without any paradigmatic proclivities. The former category of public health is not only divided in terms of disciplines but even regarding an understanding and perspective on public health apart from methodological divisions.

This paper uses the iterative approach to reformulate, revise and report conceptual and methodological levels involved while working in an inter-disciplinary platform and in an academic domain. At the end, we will consider, as an illustration, the topic of decentralization to highlight the conceptual and methodological challenges.

\section{The inter-disciplinary framework in public health}

It is now well-accepted that given the biological, medical, behavioural, cultural, institutional, sociological, economic, historical and political facets of health, an interdisciplinary framework is desirable in public health in order to make meaningful contributions [2]. However, it is necessary to understand the different theoretical and empirical levels which exist in such a framework.
The first level is to consider health (ill-health to be specific) as a problem which has to be resolved. The purpose is to understand the nature and cause or distribution and determinants of diseases. In other words, the epidemiology of diseases forms the basis for an understanding at this level. The analysis of health problems in a society requires consideration of not only the growth of productive forces but also the level of inequality in terms of class, caste and other social categories, gender, generational and geographical factors.

At the second level, health has to be considered as a need to alleviate the suffering due to health problems. It is here that the analysis of programmatic, clinical, social, psychological and cultural factors is needed. Human beings encounter health problems when they interact with each other in a given social structure, in addition to when they interact with the parasite and the ecological context in which they live and work. The analysis of institutional factors including appropriate financing strategies for optimum impact of health policies have to be considered in this context. Non-accessibility and nonavailability of health services to the people have to be explained not only in social, psychological and cultural terms but in terms of the political economy as well.

At the third level is the international domain where the focus has to be on the imbalances in the world system which sustains poverty and inequality in individual countries. With regard to health, the influence of international policies in shaping endogenous actions and programs needs to be understood. Implementation of selective primary health care, Tuberculosis program based on the DOTS strategy and the pulse polio program are examples which show the ideological dominance of a public health strategy emanating from funding agencies.

It is necessary to state that the three levels are in many ways overlapping and inter-related at both theoretical and empirical domains. This theoretical framework highlights the need to adopt a critical social epidemiology approach as against segmented disciplinary approaches which are in vogue in public health. For instance, in the present understanding of social determinants in health, holistic views are based on a systemic understanding especially with regard to interactions between people and the health service system. Distinctions like health system and health service system are posed within this framework [3-5]. Health system is considered as dynamic concept involving biological and social dimensions of the well-being of human beings. Health service system, on the other hand, is an organized complexity involving 
preventive, promotive and rehabilitative services and is only one of the many inputs required to improve the health of the people. The two systems are important for understanding social determinants or social determination (which is a term for an alternative and more radical view of social dimensions of health) and to grapple with the problem of health of the people within this framework which we call as critical public health. However, different approaches are needed for undertaking empirical studies as both systems have distinct social-political-technological subsystems. For instance, an epidemiological and managerial approach is more important for studying the health services system while a predominantly social science and epidemiological approach is needed for the health system. The health of the people is influenced by the inter-phase between the two systems in all their complexity with epidemiology providing the connecting link [6].

\section{The Political Economy Tradition}

which is subsumed in critical public health tries to locate the ill-health and health inequalities in a wider framework contextualized within the structure of the society [7]. The political economy approach in health starts with a critique of the organization of the economy and the process of changes and their implications for the health of the people [8]. These critiques largely located their perspective arguments on a wider notion of inequality prevailing in the developing and developed countries, inequitable relationships within and between countries, etc. However, it may not be correct to say that political economy approach is only a macro-critique of public health trends emerging from societal restructuring and therefore theoretical, but even understanding of social determinants can form the empirical base for the approach. The fuel for the political economy critique comes from the knowledge of pathways to ill-health such as class and other social categories, inequality research, etc. The political economy approach therefore has to constantly undertake reality checks to develop its perspective analysis. For instance, the roles of different economies, the political traditions within these economies and their policy framework which impact on health have empirical explorations within this framework [9]. One of the earliest empirical explorations influenced by a political economy approach is an ethnographic study on the introduction of Western medicine in Tamil Nadu, India by adopting a theoretical perspective which considers health not only a socially defined entity but also as a socially produced reality [10]. The holistic approach considers social determinants from the point of view of praxis where the starting point is the perspective which is linked to trends observed empirically. The approach is valuable from the point of view of policy directions and functions as a barometer for large scale deviations in structure of the society which impact on the health and well-being of the population. The poverty-ill-health nexus need to be understood from a holistic perspective wherein the outcomes are contextualized in terms of social inequality and the social forces that influence health status [11].

The second is the operational and empirical level. For instance, even identification of the poor is a challenging methodological task. As single measures like income or calorie intake are often inaccurate, several indices have been used to identify families below the poverty line. The Kerala State Poverty Eradication Mission uses the following to identify the poor. Families with four or more of the factors below are listed as poor and vulnerable: (i) No land /less than 10 cents of land; (ii) No house/dilapidated house; (iii) No sanitary latrine; (iv) No access to safe drinking water within $300 \mathrm{~m}$;(v) women headed household/presence of a widow, divorcee/abandoned lady/unwed mother; (vi) No regularly employed person in the family; (vii) Socially disadvantaged groups (SC/ST); (viii) Presence of mentally or physically challenged person/chronically ill member in the family; and (ix) Families with an illiterate adult member ${ }^{11}$. Having identified the poor, from a pragmatic and practical point of view it is important to identify the pathways that result in ill-health in order to initiate disease-eradication strategies. Generating evidence regarding the processes that lead to ill-health needs this holistic vision. Many of our current evidences regarding the relationships between ill-health and social factors including poverty do not have such multidimensionality. They are often pedantic presentations of intercorrelations and levels of significance.

The third level has to be located within the health services. As noted earlier, access to health care has become increasingly problematic to large sections of the population. The process of globalization has been associated with a number of negative trends in several countries [12] and these have become apparent at the local level which has been termed as 'glocalization' by some scholars [13]. From a health services and programme point of view, such trends have been discernible in several countries as well. Needless to add, it is important to centre-stage the primary health care approach to refocus the issue of universal access to the poor and the disadvantaged. Minimizing the suffering from poverty and ill-health necessitates recognizing the 
complexity and adopting a perspective such as critical social epidemiology which can challenge pure technocentric approaches in achieving health status.

Finally, let us examine how this theoretical and methodological tradition can be used in a study on decentralization and health. The process of decentralization and health requires a multi-dimensional approach as evident from the following identification of a number of conceptual issues.

\section{Conceptual Issues}

Decentralization is normally understood in relation to power and resources. However, in recent years a number of redefinitions have been attempted especially by the World Bank. As a parallel process, decentralization has in recent years become a tool for ushering in a neo-liberal developmental agenda. This marks a clear shift in the conceptualization of decentralization moving away from a political process to the level of total withdrawal of the State. The World Bank, which has been promoting neoliberal economic packages as a part of the Structural Adjustment programmes has come out with new conceptualizations. The World Bank in its conceptualization has placed political decentralization along with administrative, fiscal and market forms of decentralization. According to the Bank, the most complete forms of decentralization from a government's perspective are privatization and deregulation because they shift responsibility for functions from the public to the private sector. This not only under-emphasizes the political and democratic content of the process but also promotes privatization as the complete form of decentralization.

The Indian initiative on decentralization did not primarily emerge as a response to reform package but as a part of the political expedience felt by the ruling elite. Therefore, the content of decentralization initiative was much more political than managerial. The 73rd and the 74th amendment of the Indian constitution and the consequent acts in the states herald a new era in decentralized governance by making elections mandatory and preventing state governments from superseding the institutions for indefinite periods. Under the new act, a set of items would be entrusted with the local selfgovernments which comprise health and sanitation including hospitals, primary health centres, and dispensaries, family welfare, housing, drinking water, etc [14]. These institutions will also receive adequate funds to carry out these functions, including grants from the state governments and a share of certain taxes. This would be in addition to the revenue that the councils are allowed to raise and retain with them. Notwithstanding the legislation to facilitate decision-making at lower levels, the degree of political commitment will determine whether or not such institutions can become effective levels of governance with enlarged participation of the local communities [15].

Despite clarity of the central legislations in India, there are confusions regarding administrative and political forms of decentralization which is especially applicable to health services as the dichotomy between technical decisions and political control lead to conflicts and confusions. Some of these have been documented after the experience of decentralization in Karnataka and during the people's planning process in Kerala $[16,17]$. These include those related to administrative control of resources as well as that of personnel especially at the lower levels. For instance, in Karnataka, there was considerable misunderstanding among the different segments of the government regarding personnel issues such as transfers, disciplinary control, and their administrative boundaries. The Maharashtra experience shows increasing groupism on the basis of parochial considerations, failure of village councils to harness new resources, over-dependence on the government funds etc [18]. The major problem in West Bengal was with regard to allocation of resources. For schemes implemented by the local governments, funds are received in numerous unpredictable instalments throughout the year, making rational implementation of programmes extremely difficult [19].

The conflict between the professional and the political leadership is one of the challenges in the decentralization process which is probably observed in several countries. The existing health personnel do not participate at the planning process as they are largely perceived as executives. It is possible to identify a number of conflicts between the village council and the state government. The state government evolves the major chunk of the programmes that are handed down to the lower levels for implementation. All these not only result in a degree of uncertainty regarding decentralization but they also strengthen the forces of centralization to some extent.

But it is not only forces of centralization that the exploited classes have to counter but even the technomanagerial forms of decentralization in the era of Structural Adjustment. In these difficult times, a vision which places faith on people's power gets marginalized. 


\section{Methodological Challenges}

In this backdrop, it is indeed challenging to study the processes like decentralization especially given the conflicts and confusions that have arisen in recent years. This is probably the first challenge in the methodological approach. Therefore, the challenge is to understand the process as it exists, identify the gaps, probe deeper, and undertake case studies to develop assumptions and hypotheses for future studies. This may be commonly felt in many areas of public health.

More specifically, the methodological approach in many phenomena linked to public health has to focus on two issues. These are: Studying the technical and political spheres and; studying the process and dynamics.

\section{Technical and Political Sphere}

Understanding the conflict between the technical and the political spheres is one of the most important methodological challenges. This is because of a number of reasons. Firstly, there exist at considerable legal and administrative initiatives for decentralization within the political sphere while there are only marginal efforts to decentralize the health services system. Most of the decision-making within the health services system is still concentrated at the district level and above. Any efforts to understand the linkages between the political and the technical spheres have to consider this differential status.

Secondly, the conflict between the two spheres may not be revealed or may be captured only superficially in survey research as both the actors within the spheres tend to deny any such conflicts. Only adequate rapport and an in-depth probing would capture the entire gamut of conflicts and confusions between the two spheres.

Thirdly, even within the respective spheres, there exist ambiguities regarding the process of decentralization. The technical sphere tend to consider this as a political initiative while the political sphere would like to believe that without corresponding decentralization within the health service system, it is possible to have the administrative control over the technical staff such as doctors and health workers. The doctors and health workers normally eschew and resist any control by elected representatives at the lower levels, especially regarding matters related to their service. This is one of the reasons for the negligible impact of political decentralization (however limited it be) on health care. Any study on decentralization and health care has to grapple with these complexities that exist especially in a developing country context.

\section{Process and Dynamics}

Another important level of analysis which merits a methodological attention is the different dimensions of decentralization itself such as the process and the dynamics.

The 'process' of decentralization refers to an examination of the historical, legislative, policy and administrative dimensions. It also needs to examine how the functionaries both in the technical and political spheres perceives decentralization as it can be assumed that their world-views - perceptions, attitudes and approaches influence it to considerable extent. Unfortunately, there are very studies on these issues.

The 'dynamics' of decentralization includes a number of political, social and cultural variables. Prominent among them are the gender differentials among the functionaries, caste and class considerations, political affiliations etc. The study of dynamics should also include the social dimensions in relation to the village community, such as the caste-class-gender issues, political behaviour, needs of the community etc.

\section{Qualitative and Quantitative Data}

It is evident that in order to bring out some of the complexities within the process and dynamics of decentralization, to grapple with the conceptual issues and to understand the different levels of the administrative structure, a complex framework is necessary. This does not mean that any study should or can investigate the entire gamut of the process and dynamics in one go. The need for an iterative process which moves from simple level exploratory approaches to more complex and abstract constructions is to be recognized.

It is in this context that qualitative and quantitative data becomes important. Qualitative exploratory phases can help in generating hypotheses and insights into both the process and dynamics of decentralization. In-depth case studies of women elected members and their experience with governance would help in understanding the dynamics. Guide-line interviews with different sections in the community are extremely important in revealing the responses of the people towards decentralization. Group discussions within the 
community may also help in understanding the community dynamics. Similarly, deep-probing interviews with key functionaries would lead to considerable insights about the process of decentralization. Based on the qualitative data, studies can be designed to get a quantitative picture regarding the extent of felt needs within the community, gender and class differentials with regard to responses towards decentralization, budget and resource analysis etc. which will provide a quantitative dimension to the qualitative data.

\section{Conclusion}

The theme of decentralization in a specific context is discussed here as an illustration to show that a combination of macro and micro data sources is what should form the methodological repertoire of public health. This has universal implications. From a methodological point of view, a study of decentralization and its linkages with health services is most challenging and these challenges may be common to many other themes of research in public health. It is challenging because of the conceptual confusions with regard to many issues related to public health in many parts of the world. It is also challenging because of the complexity that exists within health services vis-à-vis factors which influence and shape its performance. Public health has moved forward with a quantitative leap in terms of output and it is time to assess the strengths and weaknesses and to provide an umbrella framework for consolidation. One of the great strengths of public health is its fieldwork tradition which is a legacy of early anthropologists and sociologists. Public health needs this tradition which could be used in combination with macro policy analysis. Only such a comprehensive vision can strengthen the body of knowledge of public health and which could help in making contributions which are meaningful and contextual.

\section{References}

1. Nayar KR (2002) No quick fix for social science in public health. Bulletin of the World Health Organization 80(8): 683.

2. Nayar KR (1993) Social Sciences in health: Towards a Paradigm. IASSI Quarterly 12(1\&2): 153-159.

3. Qadeer I (1985) Health services system in India: an expression of socio-economic inequalities', Soc Action 35: 199-222.
4. Bakar C, Akgün HS (2005) Health care Reforms in Turkey, endless story, Community and Health Journal, October 20(5): 339-352.

5. Akgun S (2009) Health care Quality; Systems and Alternative Methods. In: Assaf-Al-Assaf, et al eds., Health Care Accreditation Handbook, KSA, pp: 419480.

6. Nayar KR, Priya R (2007) Critical Public health: Operationalising a vision. MFC Bulletin, 323-324: 4044.

7. Mykhalovskiy E, Weir L (2004) The problem of evidence-based medicine: directions for social science. Soc Sci Med 59(5): 1059-1069.

8. Navarro V (1976) Medicine under capitalism. New York Prodist.

9. Navarro V, Shi L (2001) The political context of social inequalities and health. Soc Sci Med 52(3): 481-491.

10. Djurfeldt G and Lindberg S (1976) Pills against Poverty: A Study of the Introduction of western medicine in a Tamil village. New Delhi: Oxford and IBH Publishing Company.

11. Nayar KR (2007) Social exclusion, caste and health; A review based on the social determinants framework. Indian J Med Res 126(4): 355-363.

12. Akgün S, Bakar C (2004) Golabalization and Health; Global Problems and Possible Solutions, Hospital Life Journal 2.

13. Maeseneer DJ, Willems S, Sutter DA, Geuchte Van DML, Billings M (2007) Primary health care as a strategy for achieving equitable care: a literature review commissioned by the health systems knowledge network. Geneva: World Health Organization.

14. Government of India. The constitution Seventy Third Amendment Act, (1992) The Gazette of India Extraordinary. Part II, Section I. No. 69. 1993. New Delhi: Ministry of Law, Justice, and Company Affairs.

15. Satishchandran TR (1994) 'Inter-tier allocation of functions'. In: Mukherji A, (Eds.), Decentralization, Panchayats in the ninties, New Delhi Vikas, 24-29.

16. Satishchandran TR (1993) Democratic and Health care. The Karnataka experience. In: Antia NH, Bhatia 
K (Eds.), People's health in People's hands: A model for Democratic. Bombay, FRCH.

17. Nayar KR (2001) Politics of decentralization: Lessons from Kerala. In: Qadeer I, et al. (Eds.), Public Health and the poverty of reforms, The South Asian predicament, New Delhi, Sage.
18. Rao S (1994) Panachayti and health. Proceedings of the seminar, Bombay, FRCH, 9-10.

19. Mukherjee N, Bandopaddhyay (1994) D. New horizons for West Bengal panchayats. In: A Mukherji (Eds.), Decentralization, Panchayats in the nineties, New Delhi, Vikas. 